\title{
FUNÇÕES INTERACIONAIS NA SALA DE AULA: DA SUBORDINAÇÃO ADVERBIAL À SUBORDINAÇÃO DISCURSIVA
}

\author{
Joceli Catarina Stassi Sé \\ Erotilde Goreti Pezatti
}

\begin{abstract}
RESUMO
Levando em conta o tratamento dado à subordinaçáo adverbial no ensino e aprendizagem de língua portuguesa, este artigo apresenta contribuiçōes advindas da Gramática Discursivo-Funcional acerca da (in)dependência entre oraçóes, propondo o enquadramento da Subordinação Discursiva dentro da sistematização das relaçôes adverbiais em contexto escolar.

PALAVRAS-CHAVE: Subordinação Adverbial; Subordinaçấo Discursiva; Gramática Discursivo-Funcional.
\end{abstract}

Ensino de língua portuguesa e análise de língua em uso: rumo à confluência

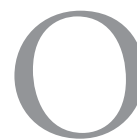

ensino de língua portuguesa nas últimas décadas tem passado por um duradouro momento de transição, interpretado pelo mundo acadêmico como um momento de crise, tema exaustivamente discutido por diversos estudos, dentre os quais o de Kraemer (2006), que aponta o ensino de língua materna na contemporaneidade como "uma arena de conflitos" (KRAEMER, 2006, p.1).

No cerne da "crise", encontra-se a gramática, vista tanto como vilã quanto como heroína, a depender da perspectiva teórica pela qual é definida no contexto escolar e, por consequência, da forma como é tratada em sala de aula por professores e alunos, que trazem crenças acerca do ensino e apren- 
dizagem de língua portuguesa pré-estabelecidas, enraizadas e dificilmente mutáveis.

Desde a proposta de ensino firmada pelos PCNs de Língua Portuguesa (1998), pautada na concepção de linguagem como forma de interação, todos os professores de língua portuguesa têm enfrentado a necessidade de conferir ao ensino de língua materna maior preocupação com o texto, com os gêneros discursivos e com a reflexão sobre o uso, tratando os conteúdos de forma cíclica, para promover maior domínio do aluno sobre a língua. Entretanto, como muitos professores, por razóes diversas, não participaram diretamente da elaboração e construçáo dessa proposta, que surgiu como um novo paradigma, acabaram por recebê-la como uma imposição burocrática do mundo acadêmico e não conseguiram alcançar o domínio das novas práticas necessárias à implementação de tal proposta, lutando (in)conscientemente por manter aquilo que acreditam ser a única forma de preparar um aluno para a vida: fazê-lo dominar a norma culta a todo custo, náo importando os meios pelos quais esse objetivo seja alcançado.

Mesmo após inúmeras tentativas do meio científico de explicitar os conteúdos de língua portuguesa a serem ensinados pela escola e as maneiras de se trabalhar com esse conteúdo, o "novo" contexto de ensino de língua materna parece não ter convencido seus participantes, fazendo com que até hoje seja necessário reafirmar essa prática pedagógica para muitos profissionais da educação.

Essa insegurança por parte dos educadores no trato com a gramática gera nos alunos sérias dificuldades de refletir sobre o uso da língua e, consequentemente, de construir textos. Isso é claramente constatado a partir do desempenho linguístico de educandos em situaçôes concretas de utilização da língua escrita em que se exige o uso da norma culta como, por exemplo, a produção de redaçóes em vestibulares, quando, teoricamente, espera-se que os candidatos mostrem bom domínio de uso da língua dentro da modalidade formal.

Esta pesquisa pretende mostrar que o problema enfrentado hoje no ensino de língua portuguesa náo reside necessariamente na falta de se colocar em prática o trabalho com o texto, mas sim na falta de uma ferramenta de reflexão linguística eficiente que se ajuste a essa realidade de ensino pautada no uso e na reflexão sobre o uso, ou seja, os professores acabam ensinando os alunos a partir do texto apenas até certo ponto, pois, no momento de trabalhar com a 
gramática, considerada um dos suportes do texto, que deve auxiliar o desenvolvimento da capacidade comunicativa do aluno, os professores se perdem e acabam se fundamentando na cobrança da regra pela regra.

É a partir do panorama acima disposto que este estudo busca, de forma geral, indicar que ações dedicadas ao ensino de gramática e à reflexão sobre seu uso deveriam se orientar por uma abordagem funcionalista da linguagem, perspectiva que embora bastante discutida e aceita, ainda é precariamente praticada nos contextos escolares brasileiros de ensino de língua portuguesa.

Por meio da discussão sobre o tratamento dado à subordinação adverbial tanto por abordagens pedagógicas quanto por abordagens funcionalistas, este estudo visa oferecer a oportunidade de se refletir sobre o alcance e a profundidade da análise linguística esperada no contexto escolar, a fim de propor uma análise transfrástica do fenômeno da adverbialidade e sua possível incorporação na sistematização das relaçóes adverbiais no contexto escolar.

Para alcançar tal objetivo nos deteremos às construçóes iniciadas por "como" que geralmente assumem a classificação de oraçóes adverbiais modais ou conformativas, mas que não apresentam uma oração nuclear à qual se subordinem, materializando-se no discurso de forma "independente" e realizando-se nos mais variados formatos, quais sejam: "como se diz", "como eu estava falando", "como eu te falei", entre outros.

O corpus da pesquisa é composto por ocorrências reais de uso extraídas do corpus oral organizado pelo Centro de Linguística da Universidade de Lisboa, em parceria com a Universidade de Toulouse-le-Mirail e a Universidade de Provença-Aix-Marselha, abrangendo as variedades que têm o português como língua oficial: Brasil, Portugal, São Tomé e Príncipe, Angola, Cabo Verde, Guiné-Bissau, e Timor Leste.

Discutiremos aqui, à luz do corpus acima disposto e do modelo da Gramática Discursivo-Funcional (HENGEVELD; MACKENZIE, 2008), doravante GDF, como lidar com as construçóes que, apesar da presença de "como", não se subordinam a nenhuma oração imediatamente anterior ou posterior, apresentando estatuto de independência semântica, morfossintática, e fonológica, constatação possível somente a partir de reflexôes sobre a função desempenhada pelos elementos que compóem o sistema da língua, reflexóes estas nem sempre oportunizadas aos alunos em sala de aula.

Vale enfatizar que este trabalho não se detém a aspectos de natureza 
didático-pedagógica; ao contrário, apresenta a preocupação já levantada por Souza e Vendrame (2011) de indicar que o aproveitamento de estudos de análise e descrição da língua portuguesa com orientação funcionalista deve ser levado em conta para que se obtenham resultados mais significativos no aprimoramento das competências linguísticas e comunicativas dos alunos, meta primordial a ser alcançada pelos educadores, de acordo com os documentos oficiais que regem o ensino de língua portuguesa no Brasil.

\section{A subordinação adverbial em discussão: o conceito de (in)depen- dência}

São muitos os estudos que se preocupam em caracterizar a coordenação e a subordinação, e a maioria deles se depara com a dificuldade que é lidar com o domínio da (in)dependência entre oraçôes.

A despeito de sua complexidade, esse fenômeno é tratado em contexto escolar com extrema superficialidade, sem que se reflita sobre suas classificações (categorizadas pelas gramáticas tradicionais), resultando num profundo desinteresse por parte dos alunos em aprofundar seus conhecimentos sobre o funcionamento da língua.

Em sua maioria, as abordagens pedagógicas se utilizam dos estudos advindos dessas gramáticas para o tratamento da (in)dependência entre oraçóes, que consideram que a ocorrência de subordinação e de coordenação depende exclusivamente de critérios formais, baseados na dependência ou independência sintática entre as oraçôes. De modo geral, as orações subordinadas são vistas como aquelas que representam uma função sintática na oração principal, enquanto as coordenadas representam oraçóes autônomas, independentes, que não funcionam como termos de outras oraçóes, e nem a eles se referem.

As gramáticas tradicionais usualmente relacionam os tipos de subordinação adverbial aos diferentes tipos de conjunção subordinativa adverbial e defendem que as oraçóes subordinadas adverbiais funcionam como adjuntos adverbiais, correlação nem sempre coerente, como observado na gramática de Silveira Bueno (1963), em que ele explicita a correspondência entre as circunstâncias expressas pelas oraçóes subordinadas adverbiais e pelos advérbios. $\mathrm{O}$ autor afirma que as relaçóes adverbiais subordinativas são tantas quantas as espécies de advérbios, o que se mostra contraditório, uma vez que apon- 
ta oito tipos de advérbio (lugar, tempo, negação, afirmação, modo, dúvida, quantidade ou intensidade, designação) e dez tipos de oraçóes subordinadas (temporais, condicionais, causais, finais, conformativas, concessivas, consecutivas, correlativas, comparativas, proporcionais) que não se correlacionam respectivamente.

Alguns gramáticos, como Bechara (2004), consideram a existência de subordinadas adverbiais propriamente ditas, que exercem função própria de advérbio e podem ser substituídas por um deles (tempo, modo, lugar - substituíveis por advérbios; e causa, concessão, condição e fim - substituíveis por locuções adverbiais) e subordinadas comparativas e consecutivas, tratadas separadamente, visto guardarem certa analogia com as subordinadas adjetivas, por dependerem de um antecedente, e só manterem relação direta com o núcleo verbal da oraçáo junto com seu antecedente. Para o autor as subordinadas adverbiais são denominadas orações complexas de transposição adverbial, podendo exercer a função de adjunto adverbial; nesse caso, o que também terá a companhia de uma preposiçâo adequada, que marcará a relação semântica da circunstância em questão.

Kury (1999) considera que subordinada é a oração dependente de um termo da frase ou de uma oração principal, exercendo, em ambos os casos, uma função sintática, o que implica que "oraçôes subordinadas são termos da frase desenvolvidos em oração" (KURY, 1999, p. 71).

Importante ressaltar que o autor, juntamente com Bechara (2004), é um dos únicos a incluir a tipologia das adverbiais locativas e modais dentre os tipos de subordinação, visto que não figuram nem na Nomenclatura Gramatical Brasileira, doravante NGB, nem na Nomenclatura Gramatical Portuguesa, doravante, NGP.

Em consequência da omissão desses tipos oracionais na NGB e na NGP, os livros didáticos, salvo raras exceções, não tratam desses tipos de construção. A exemplo disso, dos três livros didáticos analisados nesta pesquisa, a saber, Soares (2002), Cereja e Magalhães (2009) e Travaglia, Rocha e Arruda-Fernandes (2010), somente o último trata das orações adverbiais modais e, mesmo assim, não aprofunda o tratamento desse tipo de oração adverbial, nem sua sobreposição com outros valores semânticos, o que poderia engatilhar momentos de reflexão sobre a problemática de se incluir ou não as adverbiais modais entre as oraçóes subordinadas adverbiais "oficialmente" e promover 
aprendizagem significativa por meio da análise do uso que se faz dessas construçóes.

A esse respeito cumpre lembrar que para gramáticos como Cunha e Cintra (1985), Silveira Bueno (1963) e Mira Mateus et. al. (2003), as oraçóes modais são classificadas como comparativas ou conformativas, a depender do valor que a conjunção como assume, ou ainda como consecutivas ou concessivas, a depender da locução que as encabeçam, como expresso nos exemplos abaixo, discutidos por Luft (2001) em nota, e Kury (1999), respectivamente:

(01) “Trabalhou como devia." (LUFT, 2001)

(02) "Saiu sem que o notassem." (LUFT, 2001)

(03) "A voz dela, como dizia o pai, era muito mimosa." (KURY, 1999)

Segundo Luft (2001) e Kury (1999), os três exemplos acima são considerados casos de subordinação adverbial modal, muito embora a NGB e a NGP não os assumam enquanto possibilidades classificatórias para a subordinação adverbial.

Tendo em vista esse posicionamento da NGB, Kury (1999) levanta a seguinte questão: "Em que classificação se enquadra, então, as oraçóes que assim vinham sendo indevidamente chamadas?” (KURY, 1999, p. 100). Para o autor, exemplos como (3) deveriam, na falta da classificação modal, ser chamados de oraçóes conformativas.

Castilho (2010), ao analisar a língua em uso, apresenta uma classificação que coloca as modais ao lado das conformativas: o autor aponta que todas as adverbiais são dotadas de propriedades semanticamente homogêneas, mas propriedades sintaticamente distintas. O autor separa as causais, condicionais, temporais, proporcionais e finais das concessivas, comparativas, consecutivas e conformativas (modais), mostrando, por meio de teste de focalização de constituintes sentenciais, que as últimas não podem ser modificadas. Para o autor, as subordinadas adverbiais constituem sentenças que verbalizam informaçóes adicionais e funcionam em adjunção ao verbo da sentença matriz, predicando ou verificando esse escopo (CASTILHO, 2010).

Segundo o autor, o melhor critério para analisar essas construçóes é o que leva em conta, por um lado, o grau de interdependência com a sentença nuclear a que se vinculam e, por outro, o tipo de relação lógico-semântica que 
expressam, deixando-se identificar pelos traços /-encaixamento/ e /+dependência/, sendo rotuladas de hipotáticas pelo autor, assim como o fazem Neves, Braga e Dall'Aglio-Hattnher (2008).

Ao propor uma tipologia de estudo para as adverbiais, o autor se utiliza da pesquisa levantada por Neves, Braga e Dall'Aglio-Hattnher (2008), propondo as relaçóes causais, condicionais, finais, concessivas e temporais como tipos de relações semânticas sob escopo de subordinação adverbial.

Neves, Braga e Dall'Aglio-Hattnher (2008) consideram as sentenças de tempo, de causa, de condição, de concessão e outras semelhantes, como construçôes hipotáticas, isto é, sentenças que expandem as nucleares, reelaborando-as, ampliando-as ou ainda apresentando uma relação circunstancial.

Para as autoras, as chamadas subordinadas adverbiais não devem ser vistas simplesmente como um "adjunto" de uma sentença principal, uma vez que esse tipo de sentença pode se caracterizar por meio de outras propriedades, entre elas, a de articular-se com a sentença principal, distinguindo as justapostas das conectivas, e a de constituir forma própria, distinguindo as desenvolvidas das reduzidas.

Da mesma forma que a subordinação recebe um diferente equacionamento quando de sua descrição a partir do uso, o mesmo ocorre com a coordenação. Pezatti e Longhin-Thomazi (2008) demonstram que as propriedades das construçóes coordenadas vão além da independência entre oraçóes, e consideram que "a construção coordenada consiste em dois ou mais membros, funcionalmente equivalentes, combinados no mesmo nível estrutural por mecanismos de ligação" (PEZATTI; LONGHIN-THOMAZI, 2008, p. 865). As autoras, sob o escopo da perspectiva funcionalista de Dik (1997), entendem equivalência funcional a partir da equivalência entre as funçôes semânticas, sintáticas e pragmáticas dos membros coordenados, e assumem que existem diversos tipos de coordenação, entre eles: coordenação simples (entre sentenças independentes, entre sentenças dependentes, entre termos, entre predicados, entre modificadores, entre operadores), coordenação múltipla (entre diferentes constituintes dentro da mesma sentença) e coordenação simultânea (entre duplas, triplas ou n-tuplas).

Com o que foi acima destacado acerca da subordinação e da coordenação objetivamos ressaltar possibilidades de reflexão que podem ser alcançadas ao se explicar o fenômeno aqui investigado, que diz respeito à especificidade de 
construçóes do tipo "como eu estava falando" ou "como eu te falei", que, a nosso ver, não pertencem aos contextos de adverbialidade nem de coordenação entre orações. Em outras palavras, essas construçóes nem se encaixam ao estatuto de oraçóes dependentes entre si sintaticamente, configurando caso de subordinação adverbial, nem ao estatuto de independentes entre si, ou equivalentes entre si, configurando casos de coordenação entre oraçôes.

Casos semelhantes a esses chegaram a ser detectados por Garcia (1982), que reconhece esse tipo de estrutura como "caso de conflito entre a rigidez gramatical e a excelência estilística", denominando-a de "frase fragmentária". A esse respeito o autor afirma que a gramática "mandaria procurar" a oração principal dessa construção, e argumenta: "Mas o trecho é, quanto a esse aspecto, inanalisável segundo os cânones gramaticais; não obstante, constitui forma de expressão legítima no português moderno" (GARCIA, 1982, p. 118).

Dentre os estudiosos funcionalistas que analisam esse tipo de construção no português destaca-se Decat (1999), que apresenta o conceito de "desgarramento" para explicar o funcionamento dessas construçóes. A autora discorre sobre a dificuldade de se explicarem casos como o das chamadas "falsas coordenações", ou das orações subordinadas sem a matriz, e, por força disso, defende a necessidade de se abandonar o termo "subordinação" para substituí-lo por parâmetros que descrevam a relação entre as oraçóes no nível do discurso.

Garcia (2010) também fornece apontamentos sobre as propriedades das "oraçóes independentes", todavia, utilizando-se do aparato teórico da GDF, o que agrega importantes contribuiçóes para a descrição desse tipo oracional.

A autora defende a existência de um tipo de "concessiva independente", que constitui um Movimento no discurso, com a função de preservar a face ou introduzir informaçóes novas, contrárias ao que estava sendo dito.

No caso das construçóes aqui investigadas, partimos do pressuposto de que se assemelham às "concessivas independentes" descritas por Garcia (2010), ou seja, são construçóes que não pertencem ao nível da relação entre oraçôes, em um domínio morfossintático, mas sim ao nível da relação entre Movimentos, em um domínio pragmático, constituindo unidades que impulsionam o discurso para frente, apresentando uma função interacional específica, detalhada adiante. 


\section{Subordinação discursiva: refletindo sobre funções interacionais à luz da GDF}

A escolha do modelo da GDF como norte teórico para a execução desta pesquisa de base qualitativa se deu, entre outras razóes, em função desse modelo 1) considerar a língua em situações reais de comunicação; 2) optar por uma unidade de análise que extrapola o limite da oração; e 3) permitir a análise de fenômenos que envolvem interaçôes entre diferentes níveis de representação, a saber: (i) o Nível Interpessoal (NI), que trata dos aspectos formais da unidade linguística que refletem seu papel na interação entre falante e ouvinte; (ii) o Nível Representacional (NR), que trata dos aspectos semânticos das unidades linguísticas; (iii) o Nível Morfossintático (NM), que concerne todas as propriedades lineares da unidade linguística, tanto com respeito à estrutura de sentenças, orações e sintagmas quanto com respeito à estrutura interna de palavras complexas; e (iv) o Nível Fonológico (NF), que abrange a fonologia prosódica, em que cada constituinte da hierarquia prosódica faz uso de diferentes tipos de informação fonológica e não fonológica.

Entre as unidades centrais contidas no NI encontramos: (i) Movimento, a maior unidade de interação pertinente para a análise gramatical, indica o meio de expressão da intenção do falante como uma contribuição autônoma para uma interaçáo contínua, visando alcançar uma meta conversacional; (ii) Ato Discursivo, a menor unidade identificável do comportamento comunicativo, que envolve uma ilocução, o falante, o ouvinte e um Conteúdo Comunicado; (iii) Conteúdo Comunicado, contém a totalidade do que o falante deseja evocar na sua comunicação com o ouvinte, podendo ser completamente novo para o ouvinte, ou uma combinação de informação nova e dada.

No NR encontram-se as seguintes unidades: (i) Conteúdo Proposicional é um constructo mental, que não existe no espaço ou no tempo e pode ser avaliado em termos de sua verdade e qualificado em termos de atitudes proposicionais (certeza, dúvida, descrença) e/ou em termos de sua origem ou fonte (conhecimento partilhado, evidência sensorial, inferência); (ii) Episódio corresponde a um ou mais Estados-de-coisas que são tematicamente coerentes, no sentido de apresentarem unidade ou continuidade de Tempo, Locação e Indivíduos; (iii) Estado-de-coisas são entidades que podem ser localizadas em um tempo relativo e podem ser avaliadas em termos de seu estatuto de realida- 
de, podendo (não) ocorrer, (não) acontecer em algum ponto ou intervalo no tempo, sendo determináveis pela característica temporal de Indivíduos, por um lado, e de Conteúdos Proposicionais, por outro; (iv) Conceito Situacional constitui o inventário dos frames de predicação relevantes para uma língua e desempenha um papel crucial nas construçôes das representaçóes semânticas.

O NM comporta: (i) a Expressão Linguística, que consiste em pelo menos uma unidade que pode ser usada independentemente; (ii) a Oração: um conjunto de um ou mais Sintagmas caracterizados em maior ou menor extensão por um Padrão de ordenação e, também em maior ou menor extensão, por expressóes morfológicas de correctividade, principalmente referentes à regência e concordância; (iii) o Sintagma: uma configuração sequenciada de Palavras, outros Sintagmas e Orações encaixadas, e é caracterizado por ser nucleado por um item lexical trazido do NI ou do NR.

No NF, em que a expressão linguística é analisada em termos de unidades fonológicas, encontram-se as seguintes camadas: (i) Enunciado); (ii) Sintagma Entonacional; (iii) Sintagma Fonológico; (iv) Palavra Fonológica; (v) Pé e (vi) Sílaba.

Sob o escopo da GDF, acreditamos que a análise de ocorrências como (04), de Guiné Bissau, pode gerar reflexóes bastante convincentes acerca do estatuto dessas construçóes:

(04) -> inclusivamente famílias alargadas em que temos, eh, portanto, desde sobrinhos, sogros, ele, dessa mulher, enfim, cunhados e familiares que, como sabemos, eh, as famílias africanas são bastante alargadas, essa responsabilidade cai sobre os ombros da mulher. (GB95:MulherAfricana)

Embora a ocorrência em negrito se assemelhe formalmente a uma oração subordinada adverbial, tal ocorrência, dadas as suas particularidades pragmáticas, semânticas, morfossintáticas e prosódicas, permite o reconhecimento de propriedades diferentes das advindas de contextos prototípicos de subordinação.

Primeiramente, observamos que essa estrutura não é constituinte de uma oração, ou seja, não faz parte morfossintaticamente de uma oração principal representando uma oração subordinada adverbial nos padróes sustentados pela GDF no NM. Para comprovar isso basta atentar para o fato de que não 
encontramos oração principal imediatamente anterior ou posterior dentro da qual a estrutura em foco possa se estabelecer como parte integrante.

Além disso, essa construção impulsiona o discurso e contribui para a relação interpessoal, constituindo um Movimento, doravante $\mathrm{M}$, uma porção textual que pertence ao NI e que é responsável pela continuidade da interação, como se observa abaixo no exemplo (05), do português do Brasil:

(05) -> então, como eu estava falando, então, no direito romano, a mulher não tinha direitos. ela, ah, o $\mathrm{di}[\ldots], \mathrm{o}, \mathrm{a} \mathrm{ca}[\ldots]$, a pessoa que ti[...], os que tinham capacidade de, de facto, que era capacidade de ter direitos de, direitos, assim, fora os direitos normais que todos têm que é direito de escola, educação, saúde (...) (Bra80:MundoDireito)

O M em negrito instaurado pelo "como" tem a função de situar o interlocutor em relação a algo que já foi estabelecido no discurso, como se observa também em (06), outra ocorrência do português do Brasil:

(06) -> aquela lá se estiver cantando, eu sei acompanhar. eu adoro. o que você deu assim bem explicadinho, adoro, dá para acompanhar aquela lá. é uma pena que o dia que você mostrou o filme, "Ghost", não é, eu estava hospitalizada mas foi uma pena porque todo mundo falava de você na classe. que realmente você incentivou para caramba, que além de você mostrar o filme, não foi assim só para a gente ver o filme. teve um fundamento, você fez aprender, ensinar para a gente também, vendo o filme... e a letra da música. pena que não deu, que o horário da aula foi muito pouco, não é, para gente assistir o filme inteiro, para o pessoal assistir que eu não assisti. então foi assim super legal. e ela, como eu estava dizendo -> é. (Bra93:FestaEstudante)

O conteúdo que a ocorrência em (06) busca recuperar está distante na materialidade do discurso, e a função que a construção desempenha é a de chamar a atenção do interlocutor para essa informação que ficou textualmente distante, engatilhando um $\mathrm{M}$ que alerta o ouvinte e provoca sua reação.

Para ilustrar como se estabelece essa função, observemos localmente a fronteiras entre os Ms: 1) pena que não deu, que o horário da aula foi muito 
pouco, não é, para gente assistir o filme inteiro, para o pessoal assistir que eu não assisti. então foi assim super legal. e ela; 2) como eu estava dizendo; 3) é. Essa sequência evidencia o estatuto de Movimento da construção "como eu estava dizendo", que contribui para o avanço do discurso na medida em que indica para o ouvinte a preocupação do falante de resgatar em sua memória informaçôes dadas anteriormente no discurso, que não estão expressas textualmente nas porçôes textuais com as quais faz fronteira.

Há, assim, a necessidade de um olhar mais amplo para o contexto em que as ocorrências emergem, isto é, faz-se imperativo expandir a análise do plano da relação entre oraçóes para o plano da relação entre Ms.

Outro aspecto observado é que essas estruturas propiciam a ocorrência de "Atos Interativos", assinalando não só início e término de um Ato Discursivo, doravante $\mathrm{A}$, mas também início e término de um $\mathrm{M}$, como no exemplo (07) abaixo, de Angola:

(07) -> e aos treze anos lembra-se de algum drama, eh, como é que eram as noites, a sua sobrevivência e como é que conseguiu até hoje manter-se? -> bem, eh, naquel[...], na[...], naquele tempo, portanto, como eu já antes tivera dito, não é?, eu dormia hoje aqui, amanhã ali, às vezes, eh, portanto, dormia mesmo na rua assim ao ar livre. e mais tarde eu verifiquei que estava, estava, estava mesmo a caminhar muito mal, não é, estava que nem um menino de rua e no entanto eu tive de fazer o esforço, poder trabalhar um bocadinho para ver se conseguisse um tecto para mim (Ang97:JovemGaspar)

A presença de Atos Interativos como o "não é?” em (07) delimita os As representados pelas construçóes em foco e mostra que essas estruturas são unidades de informação à parte, constituindo relações entre camadas mais altas no NI.

Essas construções evocam uma informação já compartilhada em algum outro momento do desenvolvimento discursivo, tendo a função de lembrar o ouvinte ou resgatar de sua memória informaçóes já apresentadas.

No NR todas as construçóes constituem Conteúdos Proposicionais considerados verdadeiros (PÉREZ QUINTERO, 2002), sendo, portanto, sempre "factuais", como em (08), exemplo do Brasil: 
(08) -> além de ele ser o professor, ele foi o amigo da gente. então quer dizer muito mais evento desse deveria acontecer, não só com eles em si mas com a família deles, tudo. nós, como eu te falei vira uma família, a escola. então foi gostoso... (Bra93:FestaEstudante)

Nesse exemplo reconhece-se a propriedade de factualidade pelo fato de constituir ato de fala assertivo, considerado pelo falante como real, propriedade atribuída a construçóes com maior grau de sentencialidade e, por isso, com maior autonomia semântica.

O não-compartilhamento de participantes entre esses Ms e outros adjacentes é frequente, o que indica maior autonomia e menor grau de integração entre essas construçóes, como demonstrado em (09), exemplo de Portugal:

(09) -> o Visconde de Santarém foi o primeiro fogacho, no sé[...], há mais de um século, como acabo de dizer, e no início desse século, ou melhor, no final da segunda década deste século, aparece Armando Cortesão. (PT89:CartografiaPortuguesa)

No NM as construções constituem Expressões Linguísticas sem elo de dependência morfossintática com outras construçốes anteriores ou posteriores, funcionando como inserçóes, ou seja, como cortes sintáticos entre as porçôes textuais que a antecedem e a seguem, não representando casos de coordenação.

A análise mostra ainda que, em sua maioria, as formas verbais são finitas, aparecendo no modo indicativo, o que reforça a autonomia sintática dessas estruturas, como em (10) abaixo, exemplo de Timor Leste:

(10) -> de facto, como afirmou, eh, a situação política, eh, condicionou a situação linguística. antes o ensino do português era oficial, apoiado pela, governo e igreja, hoje está completamente banido. a situação actual, o aprendizagem do português foi ainda feito pela igreja, até mil novecentos noventa e dois, no Externato São José, que foi encerrado depois de doze de Novembro (TL99:Regras)

Como se atesta no exemplo acima, todas as ocorrências indicam quebra entoacional com pausa longa, identificadora de Enunciados no NF, o que 
pode ser verificado tanto pela transcrição dos inquéritos, quanto pela audição das ocorrências analisadas. Além de pausa, tanto a tessitura quanto a velocidade da construção envolvida apresentam alteração, o que traz fortes evidências da autonomia prosódica dessas construçôes.

A partir do funcionamento desses segmentos no discurso e da identificação de suas propriedades nos quatro níveis da teoria da GDF podemos dizer que essas construçóes são determinadas no NI, apresentando uma Função Interacional, denominada aqui de Função Resgate, que é codificada no NM pela conjunção "como".

Entendemos por "Função Interacional" aquela que ocorre na camada mais alta do NI, ou seja, na camada do M, e representa os aspectos discursivos das unidades linguísticas. Construções que apresentam esse tipo de função refletem uma dada orientação discursiva, manifestada na materialidade do texto por meio de pistas sinalizadoras que ora organizam o discurso, ora monitoram a interação. Observa-se, assim, uma relação de dependência discursiva entre Ms que, ao contribuir para o avanço da interação, desempenham diferentes Funções Interacionais, que podem ser de "Organização do Discurso" ou de "Monitoramento da Interação".

Ms com a Função Interacional Resgate atuam no Monitoramento da Interação, isto é, situam os participantes da situação comunicativa frente às informaçóes dadas no discurso, servindo à interação com contribuiçóes que mostram a preocupação do falante com o domínio que o ouvinte consegue ter dos assuntos que se desenvolvem no discurso. Essa função se caracteriza por ser expressa por verbos dicendi e verbos de conhecimento, antecedidos de como.

Mais evidência da atuação interacional dessas funções pode ser observada no exemplo (11), do Brasil:

(11) -> não, não gosto de jogo de bicho não. é um jogo muito legal mas eu não me adapto muito, não. não dou, não é questão de sorte, entendeu, é porque eu não gosto. entendo muito, mas não gosto. gosto muito, como eu te disse, é... corrida de cavalo, não é, que eu faço meu joguinho, ligo o rádio, escuto, torço, tudo. isso é que eu gosto. agora, jogo do bicho, lotaria esportiva, isso é um roubo! (Bra80:JogoBicho) 
O trecho "como eu te disse" não se refere a uma oração principal anterior, mas sim a algo que foi dito muito antes da oração que o antecede, a ponto de o falante querer enfatizar novamente o conteúdo que dissera anteriormente, o que mostra sua preocupação com o ouvinte. Verificamos, assim, alto grau de dependência pragmática desse Movimento com outros no discurso.

Nesse contexto, "como" protagoniza o papel de prefaciar uma inserção, de maneira a oferecer uma contribuição ao discurso ao monitorar a atenção do ouvinte para algo em específico que precisa ser ativado novamente em sua memória. Há nesse uso um apelo para evocar o conhecimento compartilhado entre os dois interlocutores, instaurado durante a interação.

Assim, destacamos aqui a possibilidade de considerar que Ms conectados por Funçóes Interacionais podem ser discursivamente dependentes uns dos outros. Essa descoberta levanta uma importante discussão sobre as relaçóes de dependência entre unidades linguísticas, fazendo-nos concluir que a melhor sugestão é abordar a noção de subordinação no domínio de porções textuais maiores do discurso.

Em função disso, nós propomos para esse tipo de subordinação que se dá no plano do discurso, a categoria de "subordinação discursiva", que nos parece bastante apropriada não apenas para os casos aqui investigados, mas para quaisquer outras conjunçóes que possam ter propriedades semelhantes de conectar Ms com diferentes Funçóes Interacionais.

\section{Considerações finais}

Neste estudo procuramos mostrar que as construçóes iniciadas por "como" sem adjacência com oração principal não devem ser classificadas como casos de subordinação adverbial nem tampouco como casos de coordenaçáo, resultado a que se chega a partir da investigação da língua em uso e da análise das funçóes desempenhadas pelos elementos no discurso, metodologia que pode e deve ser utilizada em sala de aula quando da necessidade de tratar a gramática da língua reflexivamente, como proposto pelos PCNs de Língua Portuguesa.

Defendemos aqui que a escola precisar dar menos importância à fixação de regras e mais valor à investigação do funcionamento da língua que se quer aprimorar, caminho que certamente levará o aluno a se interessar pelos fenô- 
menos linguísticos e melhorar sua competência linguística frente às quatro habilidades: falar, escutar, ler e escrever.

Esse tipo de reflexão sobre o uso e sobre a função que os elementos da língua apresentam a depender das intençôes do falante deveria ser proporcionada aos alunos por materiais didáticos e pela intervenção do próprio professor ao trabalhar com materiais que não proporcionem por si próprios esse tipo de aprendizado reflexivo.

Dessa forma, enxergar a língua em níveis e camadas poderia sim representar uma opção para a reflexão e para a análise linguística em sala de aula. Para isso, é necessário testar o modelo da GDF como ferramenta investigativa em contextos escolares, de forma a transformar professores e alunos em pesquisadores de sua própria língua, ávidos por compreender seu funcionamento, interesse que este trabalho pretende despertar também na comunidade científica.

\section{Referências}

BECHARA, Evanildo. Moderna gramática portuguesa. 37a ed. rev. e ampl. Rio de Janeiro: Lucerna, 2004.

BRASIL. Ministério de Educação, Cultura e do Desporto. Secretaria de Ensino Fundamental. Parâmetros Curriculares Nacionais - Lingua Portuguesa. Ciclo II- 5ª-8 série. Brasília, DF: MEC/SEF, 1998.

CASTILHO, Ataliba. T. de Nova Gramática do Português Brasileiro. São Paulo: Contexto, 2010.

CEREJA, William Roberto; MAGALHÁES, Thereza Cochar. Português-linguagens, vol. 6, 60 ano do ensino fundamental. Ensino fundamental II. São Paulo: Atual, 2009.

CUNHA, Celso; CINTRA, Lindley. Nova gramática do português contemporâneo. Rio de Janeiro: Nova Fronteira, 1985.

DECAT, Beatriz. Por uma abordagem da (in)dependência de cláusulas à luz da Noção de 'unidade informacional'. Scripta, Belo Horizonte, PUC-MINAS, v. 2, n.4, $1^{\circ}$ sem., p. 23-38, 1999.

DIK, Simon Cornelis. The Theory of Functional Grammar. Berlin: Mouton de Gruyter, 1997.

GARCIA, Otto. Comunicação em Prosa Moderna. Fundação Getúlio Vargas, $10^{a}$ Ed., 1982. 
GARCIA, Talita Storti. As relaçóes concessivas no português falado sob a perspectiva da Gramática Discursivo-Funcional, 2010. Tese (Doutorado em Estudos Linguísticos - Área de concentração: Análise Linguística). Unesp, Câmpus de São José do Rio Preto.

HENGEVELD, Kees; MACKENZIE, Lachlan. Functional Discourse Grammar: A typologically-based theory of language structure. Oxford: Oxford University Press, 2008.

KRAEMER, Márcia Adriana Dias. Ensino Gramatical de Língua Materna: uma arena de conflitos. Revista Letra Magna, Ano 03- n.04 -10 Semestre de 2006.

KURY, Adriano da Gama. Novas liçôes de análise sintática. 7a. Ed. São Paulo: Ática, 1999.

LUFT, Celso Pedro. Novo Manual de Português. São Paulo: Globo, 2001.

MATEUS, Maria Helena et. al. Gramática da lingua portuguesa. 7a. ed. Lisboa: Editorial Caminho, 2003.

NEVES, Maria Helena de Moura; BRAGA, Maria Luiza; DALL'AGLIOHATTNHER, Marize Mattos. As construções hipotáticas. In: ILARI, Rodolfo; NEVES, Maria Helena de Moura. (Orgs.) Gramática do Português Culto Falado no Brasil: classes de palavras e processos de construção. vol. II, Campinas, SP: Editora da Unicamp, 2008.

PÉREZ QUINTERO, M. J. P. Adverbial Subordination in English: A Functional Approach. In: Language and Computers: Studies in Practical Linguistics, no. 41. Amsterdam: New York, 2002.

PEZATTI, Erotilde Goreti; LONGHIN-THOMAZI, Sanderléia Roberta. A coordenação. In: OLIVEIRA, Dermeval da Hora; SILVA, Camilo Rosa. (orgs.). Para a história do português brasileiro: abordagens e perspectivas. João Pessoa: Ideia Editora Universitária, v. VIII, p. 135-37, 2010.

SILVEIRA BUENO, Francisco. Dicionário escolar da língua portuguesa. 4ed. Rio de Janeiro: MEC, 1963.

SOARES, Magda. Português: uma proposta para o letramento. São Paulo: Moderna, 2002. (Coleção didática 5a/8a séries). 


\title{
INTERACTIONAL FUNCTIONS IN THE CLASSROOM: FROM ADVERBIAL SUBORDINATION TO DISCOURSE SUBORDINATION
}

\begin{abstract}
Taking into account the treatment offered to adverbial subordination in teaching and learning Portuguese, this article presents contributions from Functional Discourse Grammar concerning clausal (in)dependency and the acceptance of Discourse Subordination in the systematization of adverbial relation in teaching contexts.
\end{abstract}

KEYWORDS: Adverbial Subordination; Discourse Subordination; Functional Discourse Grammar.

Recebido em 30/03/14 Aprovado em 0506/14 